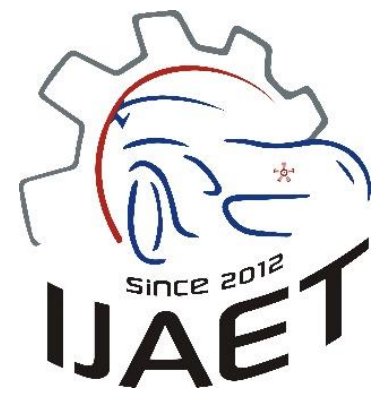

e-ISSN: 2146 - 9067

International Journal of Automotive

Engineering and Technologies

journal homepage:

https://dergipark.org.tr/en/pub/ijaet

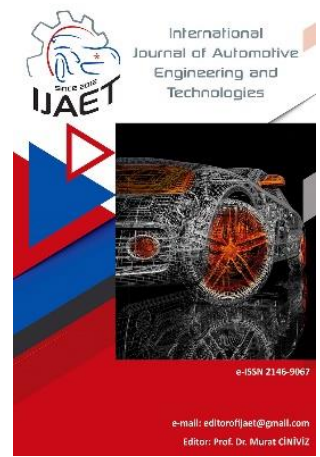

Original Research Article

\title{
Determination of the effects of the simultaneous use of ethanol- diesel emulsion as the main fuel and post-injection fuel in a diesel engine on engine performance and emissions
}

Hüseyin Gürbüz ${ }^{1 *}$

1* Automotive Division, Department of Mechanical Engineering, Şırnak University, Şırnak 73000, Turkey

\section{ARTICLE INFO}

Orcid Numbers

1. 0000-0002-3561-7786

Doi: $10.18245 /$ ijaet.1002854

* Corresponding author

huseyinngurbuz@gmail.com

Received: Sep 30, 2021

Accepted: Dec 26, 2021

Published: 31 Dec 2021

Published by Editorial Board Members of IJAET

(C) This article is distributed by Turk Journal Park System under the $\mathrm{CC} 4.0$ terms and conditions.

\begin{abstract}
In this article, the effects of heated ethanol diesel blend on emissions were investigated experimentally. Additionally, the effect of post-injection strategies on emissions in the AVL Boost model engine, which has the same characteristics as the experimental engine running with ethanol-diesel emulsion fuel, was investigated as a simulation. In a special designed mixer, the ethanol-diesel emulsion (E10) formed with 10\% ethanol and $2 \%$ isopropyl was stirred at $40{ }^{\circ} \mathrm{C}$. The emulsion temperature was kept constant between $35-40{ }^{\circ} \mathrm{C}$ during the experiments. The homogeneous residence time of the blended fuel improved with increasing temperature. Post-injection strategy tests at 2 different crank angles were mathematically analyzed separately for ethanol diesel emulsion as a postinjection fuel in the simulation software. NOx emissions decreased with E10 fuel at low speeds compared to E0 fuel. Slightly increased NOx emissions in the Bpi2 strategy compared to the Bpil strategy. In addition, soot emissions reduced with Bpil at all engine speeds. The brake specific fuel consumption with the E10 blend increased by $4.36 \%$ compared to E0. However, the brake specific fuel consumption was slightly reduced in the Bpi1 and Bpi2 injection strategies tests compared to the E10 experiment.

Keywords: Heated emulsion, ethanol, post injection, diesel engine
\end{abstract}

\section{Introduction}

Since the problems related to global warming have increased in recent years, the necessity of eliminating the causes that increase global warming has become more acceptable. Fossil fuels are the most important factor that increases global warming, which has serious damage to human health and the environment [1]. Although the transportation sector, where mostly fossil fuel derivatives are used, causes too much greenhouse gas emissions, it still continues to meet its energy needs mostly with diesel and gasoline [2, 3]. For these reasons, emission standards continue to be updated to further reduce greenhouse gas emissions [4]. NOx emissions, which is the most important greenhouse gas, occur too much due to the high temperatures created by diesel combustion [5]. Light alcohols such as ethanol are important alternative renewable fuels to reduce NOx emissions $[6,7]$. Although ethanol is not used directly in diesel engines due to its low cetane number, high autoignition temperature and high heat of vaporization, it can be used with mixing, emulsification, fumigation and dual fuel 
methods [8-11]. In addition, since the viscosity of ethanol is low, the atomization of the fuel blended with diesel sent to the cylinder improves and provides a better mixture with air [12].

The mixture and emulsion methods are more advantageous than the fumigation method because a new fuel system, electronic control unit and engine design change are necessary [13]. However, alcohols and diesel fuel don't mix homogeneously due to their polar structures and problem of stability and separation of blends [8]. Even so, the solubility of anhydrous ethanol in diesel is better than that of aqueous ethanol [14-16]. In the emulsion method, an emulsifier should be added to the ethanol diesel mixture to prevent phase separation, increase the solubility of ethanol in diesel and provide homogeneous mixture [17-19]. Therefore, since diesel fuel is nonpolar, it is possible to obtain thermodynamically more stable a mixture by adding heavy polar alcohols with different molecular structure such as propanol, butanol, isopropyl, as emulsifiers and solvents [20]. Furthermore, heating the emulsion increases the homogeneously residence time of the mixture [21]. The use of ethanol in diesel engines increases the ignition delay time [22]. Long ignition delay causes NOx molecules to increase and $\mathrm{HC}$ molecules to fall [23]. In addition, ethanol is an important renewable energy resource for the European Parliament Directive $2009 / 28$ / EC, which encourages to meet $10 \%$ of energy by using renewable energy sources [24, 25].

Rakopoulos et al. [26] they investigated the effects of different ratios of ethanol blends on emissions and engine performance in a diesel engine. They used a 5\%, $10 \%$ and $15 \%$ (by volume) ratio ethanol blend. As a result of the tests, NOx emissions were decreased and HC emissions increased due to the decrease in thermal efficiency. Rossomando et al. [27] investigated the effects of ethanol diesel mixtures on emissions and performance by combustion modeling. They identified a reduction in soot particulate matter and NOx emissions, but some increase in $\mathrm{CO}_{2}$ emission. Huang et al. [28] investigated the effects of ethanol on emissions at different load and different engine speeds in a diesel engine. They reported that with the increase in ethanol ratio in the blend, thermal efficiency decreased and $\mathrm{CO}$ emission reduced at medium and high loads, but increased at low engine load. As seen in the literature, the application of ethanol by emulsion method in diesel engines has a significant contribution to reducing pollutant emissions. However, the fuel consumption and pollutant emission rate are largely due to fuel spray form, fuel evaporation, combustion processes and fuel injection strategies [29]. For example, pilot injection is very effective in reducing NOx emissions, while post - injection reduces soot emissions [30]. Padala et al. [31] investigated the effects of different proportions of ethanol blends and different injection times on diesel combustion and emissions. In single spray tests, they determined that NOx emissions increased with increasing ethanol content in the blend, but $\mathrm{CO}$ emissions decreased. Also, they found that the maximum pressure inside the cylinder increased with increasing ethanol content in the blend. Arrègle et al. [32] applied different postinjection strategies to reduce soot emissions in the diesel engine. They concluded that they significantly reduced post-injection soot emissions. Lopez et al. [33] applied different injection times and different emission improving methods to reduce soot emissions. Soot emission decreased with delay of post injection start time. Tsurushima et al. [34] in their study examining the effects of post injection, they stated that $\mathrm{HC}, \mathrm{CO}$ and particulate matter emissions decreased with post injection. The main reason for this reduction was the combustion of the remaining fuel from the main injection with post injection into the combustion chamber.

Due to the difficulty of applying experimental studies and the high costs, it is possible to obtain mathematical results for many possible situations by using many different conditions in the models created with simulation programs. In this way, steps that are more accurate can be taken in experimental studies to avoid unnecessary time and cost loss. Nabi et al. [35] modeled a naturally aspirated diesel engine in a simulation program and examined the effect of many parameters such as different injection times, different engine speeds and different compression rates on combustion and performance. As a result of simulation tests, they found that with increasing injection time, 
brake specific fuel consumption increased and engine torque decreased. Tutak et al. [36] using the CFD method, they investigated the effects of ethanol-diesel mixture with high ethanol content and injection timing on emissions. Also AVL sample models were used for emissions models. They found a reduction in soot emissions and an increase in NO emissions. They also discovered that NO emissions increased and soot emissions decreased when post-injection time was postponed and used high proportion of ethanol blend.

In this study, ethanol-isopropyl-diesel emulsion, the temperature of which was kept constant between $35-40{ }^{\circ} \mathrm{C}$ during each experiment, was experimentally investigated by injecting it into the inlet of the diesel engine with a gasoline injector. At the other stage, unlike other studies in the literature and ours, the effects of directly injecting this high-temperature ethanol diesel emulsion into the cylinder as a post fuel instead of ethanol or diesel fuel as the final (post) fuel were mathematically investigated in the simulation software.

\section{Experimental methodology}

This study was carried out in four steps. In the first stage, the engine map and operating characteristics of the 3-cylinder turbocharged diesel engine, the characteristics of which are shown in Table 1, were determined experimentally by using diesel fuel. Then, under the same conditions, the ethanol-diesel mixture containing $10 \%$ ethanol was injected directly into the cylinder, and the engine characteristics and emission values were experimentally determined. In the second step, the test engine model was created with AVL BOOST 2016v software. The experimental data obtained using diesel and E10 fuel were validated by tests with this model engine. Also, the mean effective pressure obtained as a result of the real experiments carried out with E10 fuel and the ME10 mean effective pressure data curve obtained with the simulation model engine were compared in Figure 1. It was determined that the simulation and real experiment mean effective pressure curves almost completely overlapped and the results were very close level to each other. Thus, the model engine constructed with AVL Boost software was calibrated for post injection tests and its reliability was found to be acceptable. In the third step, injector model of the engine was created in addition to the same model engine. Moreover, post-injection tests were mathematically carried out using 10\% ethanol-diesel blend fuel (E10) for post and main injection in the simulation model engine. In the last step, the experimental data were compared with the model and post-injection test results.

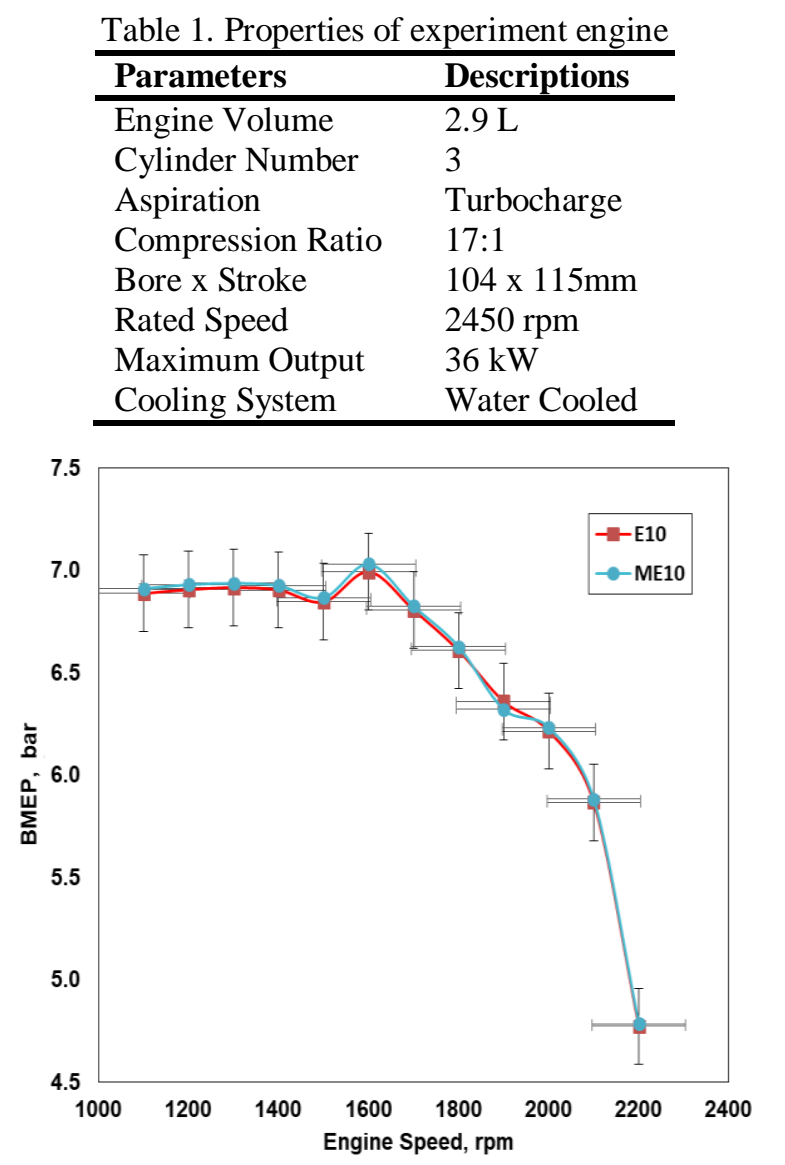

Figure 1. Comparison of simulated and real test curves of mean effective pressure

A DC electric dynamometer was used to load the experiment engine. In-cylinder pressures were measured with pressure transducer (AVL GH14P) combined with a data acquisition system and a charge amplifier (Kistler 5018A). To obtain the heat release rate (HRR), a singlezone model was used, assuming that the air fuel mixture and the temperature were homogeneous over the entire cylinder volume. In addition, in the AVL Boost program, heat transfer coefficient and heat release rate (HRR) were calculated using Woschni correlation with thermodynamics and cylinder pressure data according to the first law of the Woschni 1978 heat transfer model [37, 38]. The Woschni model is shown in Eq. 1 [39]. 
$a_{w}=130 \cdot \mathrm{D}^{-0.2} \cdot p_{c}^{0.8} \cdot T_{C}^{-0.53} \cdot\left[C_{1} \cdot C_{m}+\right.$

$\left.C_{2} \cdot \frac{V_{D} \cdot T_{C, 1}}{P_{C, 1} \cdot V_{C, 1}} \cdot\left(P_{C}-P_{C, 0}\right)\right]^{0.8}$

In Eq. 1, $C_{1}=2.28+\frac{\mathbf{0 . 3 0 8 \mathrm { Cu }}}{\mathbf{C m}}, \mathrm{C}_{m}$ is the average piston speed and $\mathrm{C}_{u}$ is the circumferential speed. Coefficient is taken as 0.00324 in direct injection engines. $V_{D}$ represents the displacement volume per cylinder, $D$ represents the diameter of the cylinder, $\boldsymbol{P}_{\boldsymbol{C}, \mathbf{0}}$ indicates the pressure in the cold cycle, $\boldsymbol{P}_{\boldsymbol{C}, \mathbf{1}}$ indicates the pressure value when the suction valve is closed, $\boldsymbol{T}_{\boldsymbol{C}, \mathbf{1}}$ indicates the temperature value when the suction valve is closed. In addition, HRR was calculated by using the analysis model created in the matlab program and Eq. $2[40,41]$.

$\frac{d Q_{n e t}}{d \theta}=\frac{k}{k-1} p \frac{d V}{d \theta}+\frac{1}{k-1} V \frac{d V}{d \theta}$

Where: $\mathrm{k}$ is ratio of the specific heats, $p$ is incylinder combustion pressure, $V$ is in-cylinder volume, $\theta$ is crank angle (CA) deg, $Q_{\text {net }}$ is net heat released during combustion.

Gas emissions containing NOx, HC, $\mathrm{CO}$ and $\mathrm{CO}_{2}$ were measured with the AVL Dicom 4000 exhaust emission analyzer. Also, smoke was measured with the AVL 415S filter paper smoke meter. K-type thermocouples were used for fuel temperature, exhaust gas temperature and radiator water temperature measurements.

Due to the difference in density of ethanol and diesel, the mixture is heterogeneous. The mixtures made with these fuels have a clearly visible phase separation within a few minutes. Emulsifier should be added to diesel-ethanol mixtures to prevent heterogeneous structure and phase separation. When fuels (ethanol and diesel) and a solvent are sprayed into a vessel in a pressurized manner, the phase separation time of the mixture is considerably prolonged. However, as the ethanol content in the mixture increases, this time is shortened again in minutes. Therefore, the mixture made with heated ethanol becomes easier and faster homogeneous structure. [14, 42]. Before starting the experiments, phase separation times were examined by heating ethanol diesel mixtures prepared in tubes with different proportions of ethanol. Thus, optimum temperature and mixing ratio for the blends were determined. Table 2 shows the time taken for partially heterogeneous crystalline states and completely heterogeneous phase separation states of emulsions prepared with different ratios of ethanol, diesel and isopropyl alcohol as emulsifier at different temperatures. The phase separation of emulsion fuel samples with high ethanol content was observed by video recording method for 5 hours. The phase separation times of the emulsions with ethanol mixing ratios between $5 \%$ and $30 \%$ are shown in Figure 2. Temperature of the emulsions used in the experiments, it was increased to $40{ }^{\circ} \mathrm{C}$. This temperature was kept constant at average temperature of $35^{\circ} \mathrm{C}$ with a thermostat during the experiment. The proportion of isopropyl alcohol used in all blends is $2 \%(\mathrm{v} / \mathrm{v})$. The solubility of fuels depends on the water content of ethanol, the hydrocarbon molecule and temperature of the fuels [43]. Thence, ethanol with a purity of 99.9\% was used in blended fuels for the experiments.

The Bernoulli equation (Eq. 3) was used to determine the amount of fuel injected into the cylinder based on the crank angle degree (CAD) [44]. The exit velocity of the fuel through the injector nozzle hole is obtained using Eq. 4 [45]. The injector was modeled for post-spraying at two different times. The first blend postinjection (Bpi1) was applied after 3 CAD in the end of main injection, and the second blend post injection (Bpi2) was applied at the same proportions after $7 \mathrm{CAD}$.

$\frac{V_{1}^{2}}{2}+\frac{P_{1}}{\rho}+g Z_{1}=\frac{V_{2}^{2}}{2}+\frac{P_{2}}{\rho}+g Z_{2}$

$V_{2}=\sqrt{\frac{2 \Delta P}{\rho}}$

The variables $P_{1}, V_{1} Z_{1}$ refer to the pressure, height and speed of the fluid at point 1 (nozzle inlet), whereas the variables $P_{2}, Z_{2}, V_{2}$ refer to the speed, pressure, and height of the fluid at point 2 (nozzle outlet). $\boldsymbol{\rho}$ is density.

\section{Result and Discussion}

In this section, the experimental results of the effects of E0 (diesel) and E10 (10\% ethanol blend) fuels on pollutant emission and performance are presented below. The test results of the model created in AVL Boost program are presented. Also, the model simulation results of Bpil (1. Post-injection) and Bpi2 (2. post-injection) post-injection strategies are given. 
Table 2. Effect of temperature on phase separation times of emulsions

\begin{tabular}{|c|c|c|c|c|c|c|c|}
\hline Temperature & & $\mathbf{E 5}$ & E7.5 & E10 & E15 & E20 & E30 \\
\hline \multirow{2}{*}{$7^{\circ} \mathrm{C}$} & Crystal structure & 4. $\min$ & 4. $\min$ & 4. $\min$ & 2. $\min$ & 4. $\min$ & 1. $\min$ \\
\hline & Phase separate & 8. $\min$ & 8. $\min$ & 7. $\min$ & 5. $\min$. & 5. $\min$ & 1.5. $\min$ \\
\hline $25^{\circ} \mathrm{C}$ & Crystal structure & no & no & no & 5. hours & 2. hours & 1.5 hours \\
\hline (3 day) & Phase separate & 3. day & 3. day & 12. hours & 6. hours & 2.5. hours & 1.5 hours \\
\hline $30^{\circ} \mathrm{C}$ & Crystal structure & no & no & no & no & no & yes \\
\hline (5 hours) & Phase separate & no & no & no & no & no & yes \\
\hline $35^{\circ} \mathrm{C}$ & Crystal structure & no & no & no & no & no & yes \\
\hline (5 hours) & Phase separate & no & no & no & no & no & yes \\
\hline $40^{\circ} \mathrm{C}$ & Crystal structure & no & no & no & no & no & no \\
\hline (5 hours) & Phase separate & no & no & no & no & no & no \\
\hline $45^{\circ} \mathrm{C}$ & Crystal structure & no & no & no & no & no & no \\
\hline (5 hours) & Phase separate & no & no & no & no & no & no \\
\hline $50{ }^{\circ} \mathrm{C}$ & Crystal structure & no & no & no & no & no & no \\
\hline (5 hours) & Phase separate & no & no & no & no & no & no \\
\hline
\end{tabular}

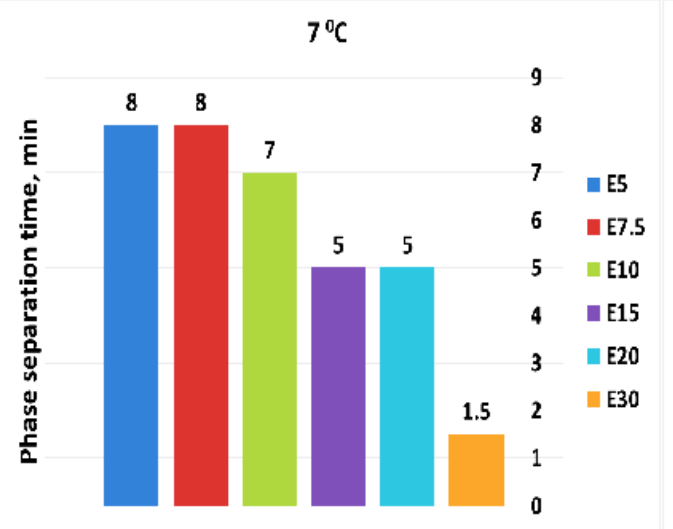

$30^{\circ} \mathrm{C}$

within 5 hours

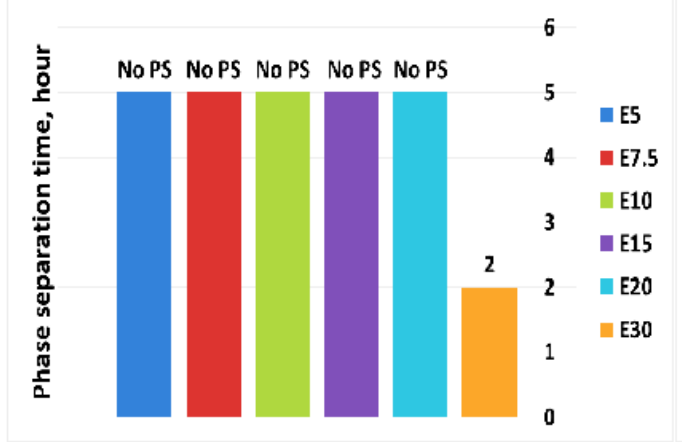

$40^{\circ} \mathrm{C}$

within 5 hours

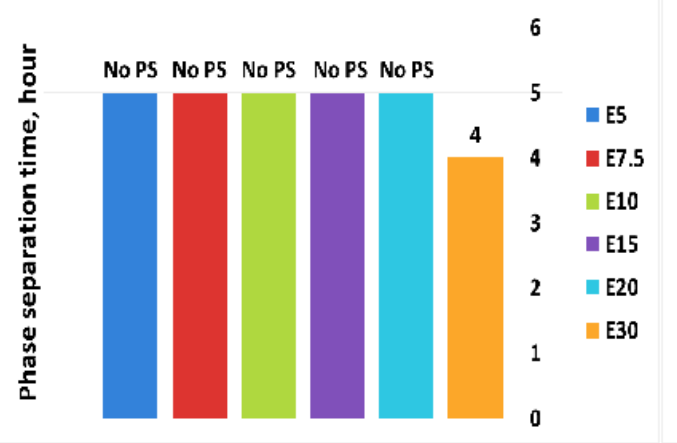

$25^{\circ} \mathrm{C}$

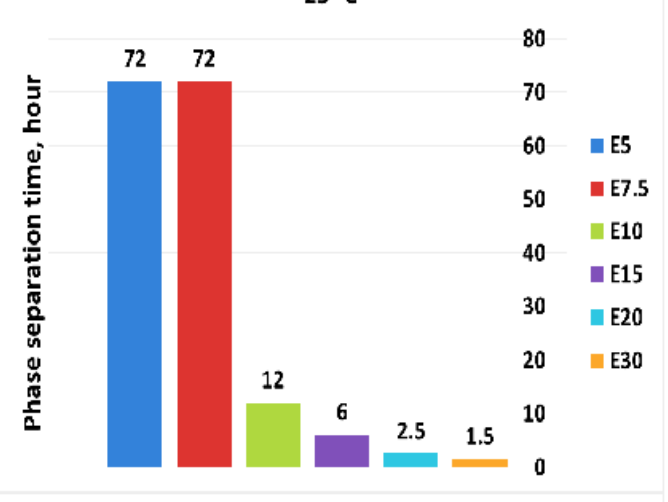

$35^{\circ} \mathrm{C}$

within 5 hours

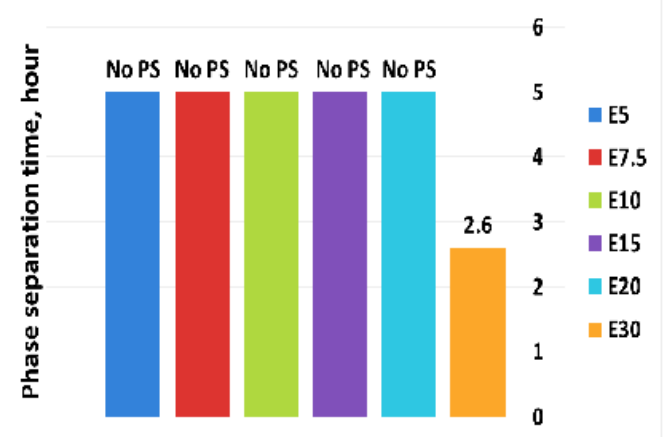

$45^{\circ} \mathrm{C}$

within 5 hours

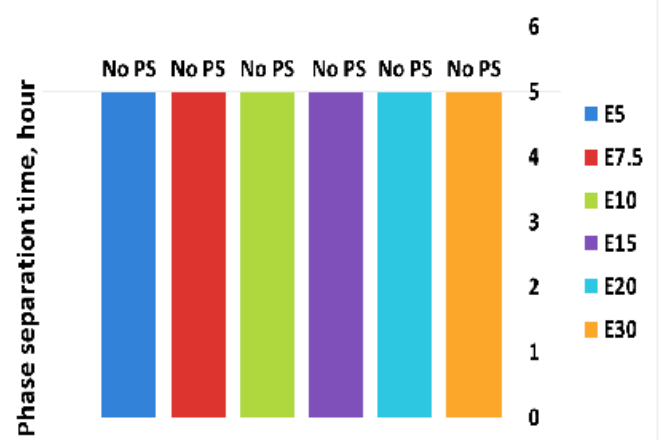

Figure 2. The phase separation times of ethanol diesel emulsions within 5 hours

All maps in Figures 3-5 show the engine map of NOx, soot and brake specific fuel consumption, respectively. The graphs show the experimental and model results of E0 and E10 fuels and the simulation results of Bpi1 and Bpi2 strategies. NOx emissions decrease with E10 fuel at low 


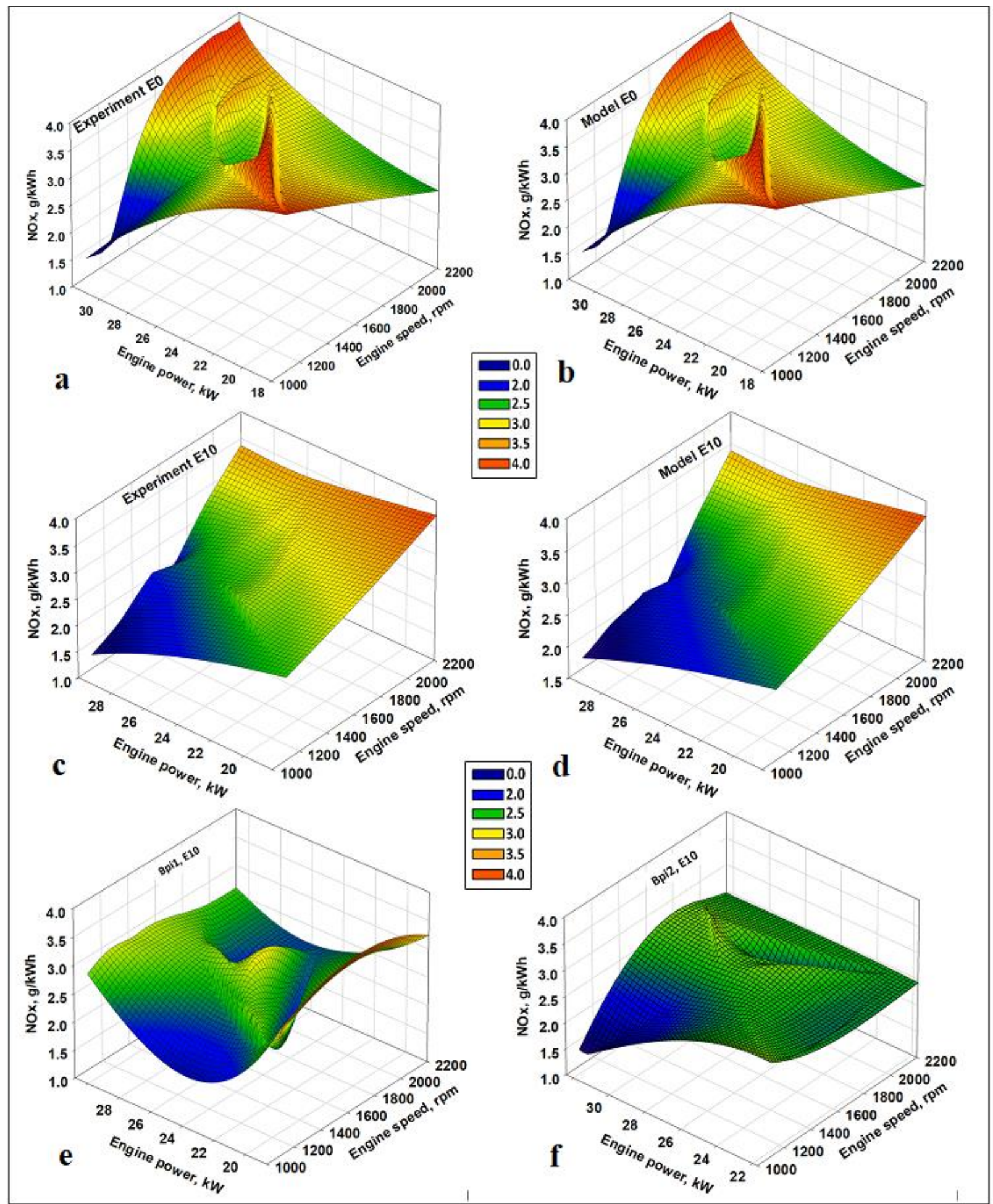

Figure 3. Emissions maps of NOx using a) Exp. E0 b) ME0 c) Exp. E10 blend d) ME10 blend e) Bpi1 inj. and f) Bpi2 inj.

speeds compared to E0 fuel. However, it can be seen that fuel E10 produces higher NOx emissions at high speeds. This increase may be due to the temperature rise in the cylinder depending on the high evaporation temperature of ethanol, the autoignition temperature of the mixture and the proportion of ethanol in the emulsion $[46,47]$. In addition, with the addition of ethanol to the mixture, a decrease in $\mathrm{NO}_{\mathrm{x}}$ emissions can be observed with the lower calorific value of the emulsion fuel [12]. Overall, given the map of Figure $3 \mathrm{f}$, there was some increase in NOx emission in the Bpi2 strategy compared to the Bpil strategy. If there is an excessive delay post-injection without changing the spray amount, a reduction in NOx emission may be observed [48]. 


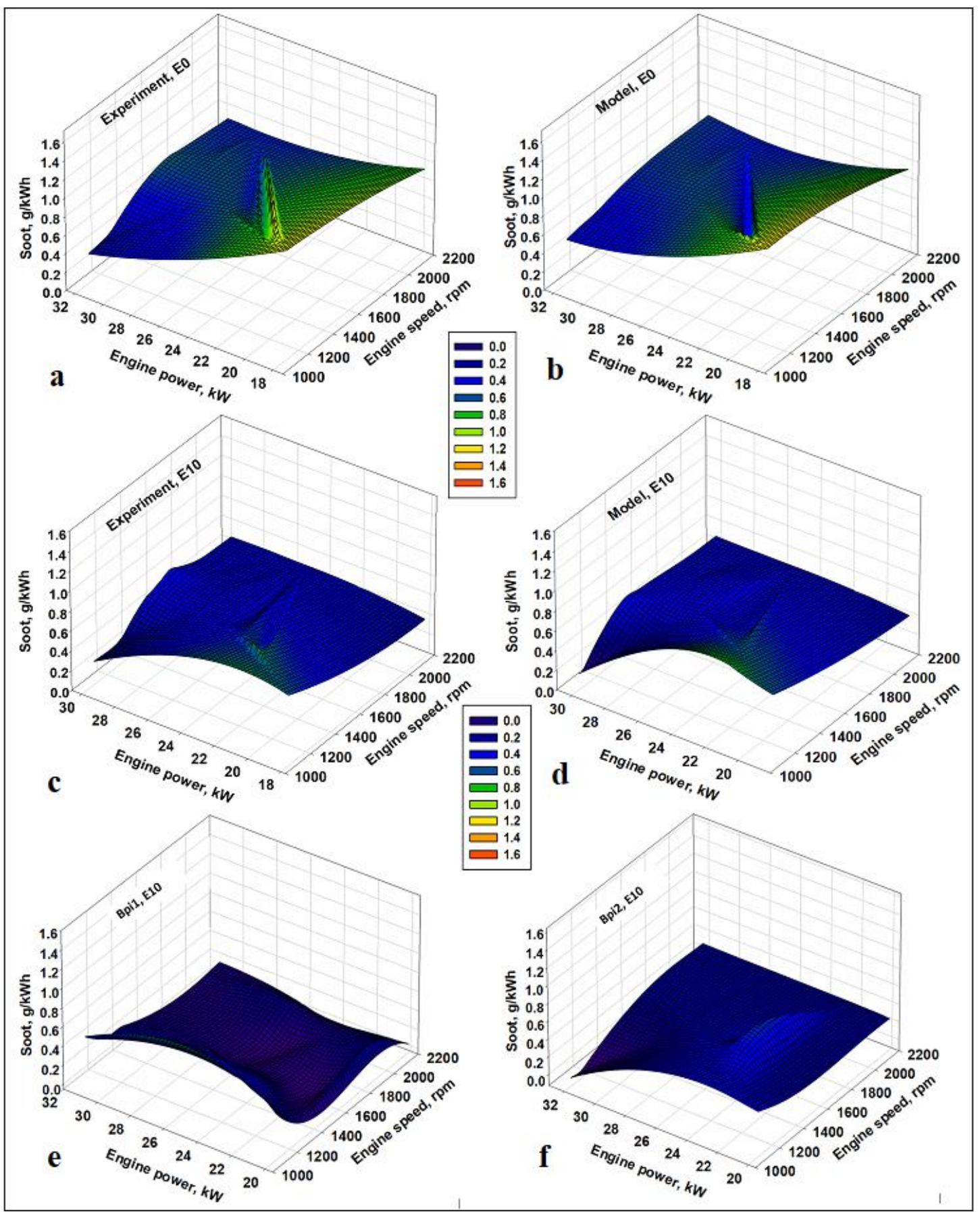

Figure 4. Emissions maps of soot using a) Exp. E0 b) ME0 c) Exp. E10 blend d) ME10 blend e) Bpi1 inj. and f) Bpi2 inj

The low volatility and high oxygen content in the biodiesel mixture, such as the ethanol-diesel blend, have been reported to be effective parameters to significantly reduce soot emissions [49]. Soot emission decreased with E10. Reducing the viscosity due to the increased temperature of the emulsion may have resulted in better atomization of the fuel and better combustion. Soot emissions reduced with Bpil at all engine speeds. Post injection near the end of the main injection is highly effective in reducing soot emissions because of acceleration of combustion in the last phase [50].
The brake-specific fuel consumption (BSFC) fields have a roughly parabolic shape. The best point consumption was $252-255 \mathrm{~g} / \mathrm{kWh}$ with E10 blend between 1400-1600 rpm. When the total fuel consumption was evaluated, the brake specific fuel consumption with the E10 blend increased by $4.36 \%$ compared to E0. In Bpil and Bpi2 post injection strategies simulation tests, brake specific fuel consumption decreased by $1.04 \%$ and $3.06 \%$, respectively, compared to the E10 experiment. This reduce in BSFC can be observed with the increase of green and blue areas in Bpi1 and Bpi2 maps. 


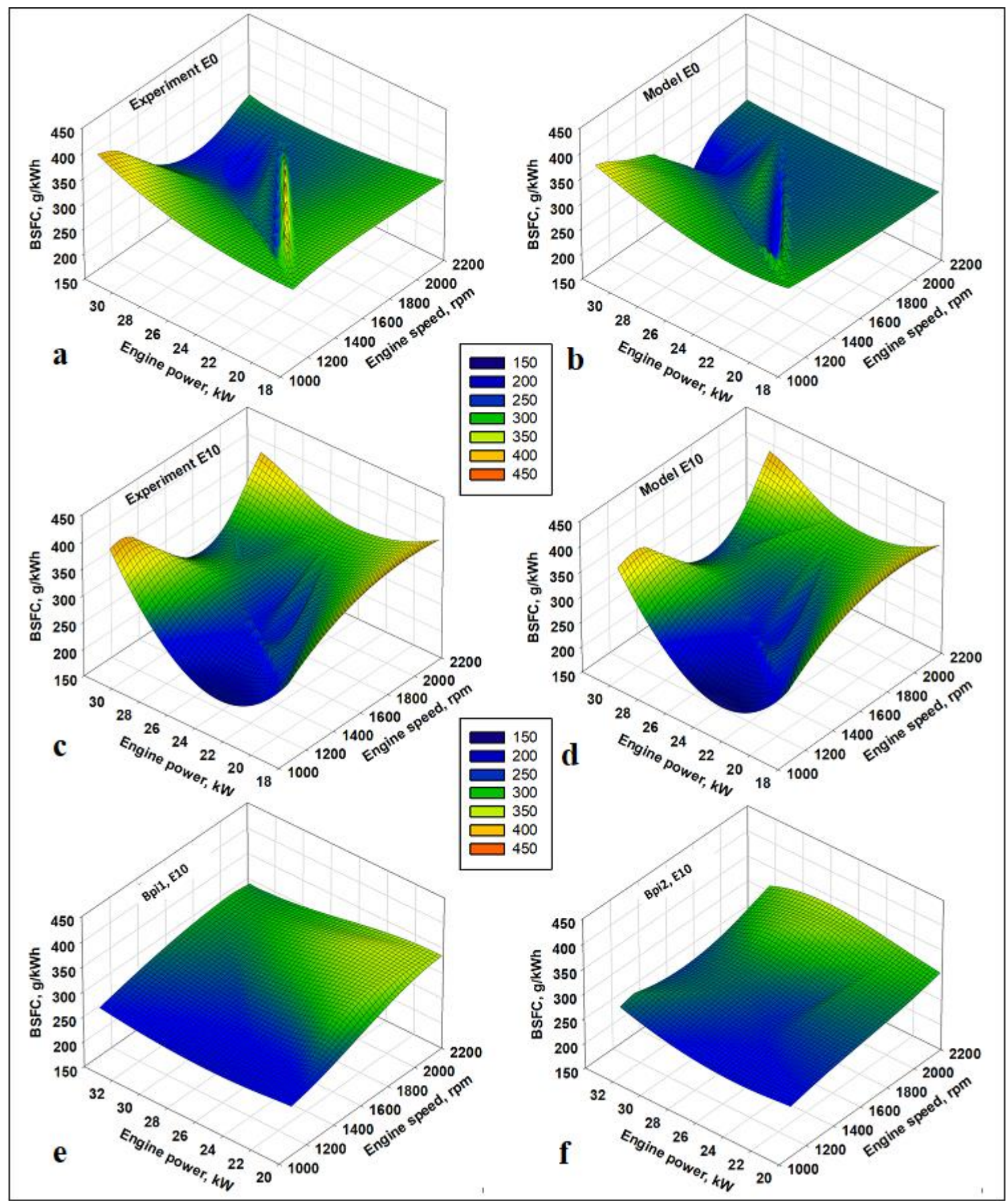

Figure 5. Maps of BSFC using a) Exp. E0 b) ME0 c) Exp. E10 blend d) ME10 blend e) Bpi1 inj. and f) Bpi2 inj.

Figure 6 shows the change in brake mean effective pressure (BMEP) according to engine speed. BMEP is a result of the air-fuel mixture. Thus, as engine speed increases, BMEP decreases. The BMEP increased at a speed of $1600 \mathrm{rpm}$, and then decreased over the entire engine speed range. However, BMEP increased significantly with post injections compared to E10 fuel.

\section{Conclusions}

In this study, combustion characteristics, soot exchange and NOx emissions of a diesel engine operating with diesel and heated ethanol-diesel mixture were investigated experimentally. In addition, emulsion fuel was injected directly into the cylinder in different strategies as a postinjection fuel in the simulation model engine and its effects on pollutant emissions and performance were investigated.

The main results are summarized below: The use of ethanol diesel blend led to slightly reducing BMEP in comparison to diesel over the entire range of high engine speeds ( $1600 \mathrm{rpm}$ to $2200 \mathrm{rpm}$ ), but with the mix, the BSFC increased slightly. Furthermore, BMEP was 
increased with post injections (Bpi1 and Bpi2). Lost BMEP can be recovered by increasing the consumption of the diesel-ethanol blend or by applying multiple simultaneous post-injection strategies.

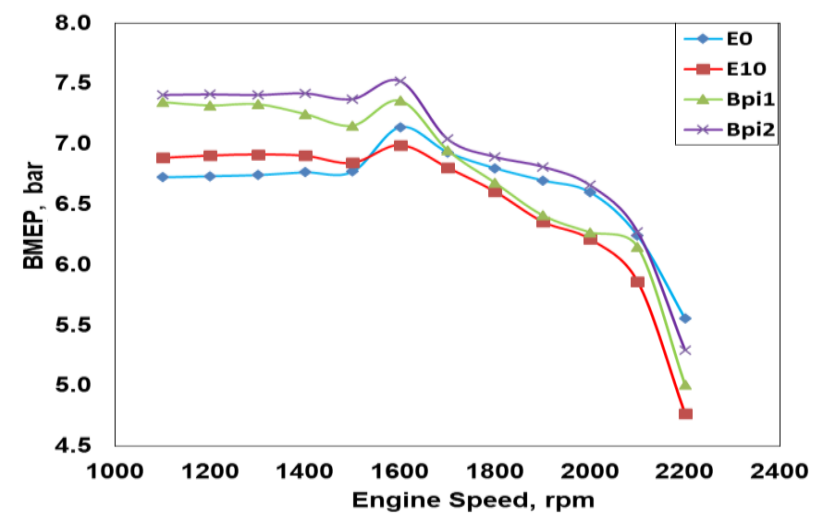

Figure 6. Effect of ethanol and injection strategies on brake mean effective pressure

NOx emission significantly reduced with E10 blend especially at medium and low engine speeds. In addition to this reduction, NOx emission was decreased very effectively with Bpi1 and Bpi2 post-injection strategies at all engine speeds in the model engine fueled with E10 emulsion. The use of ethanol with emulsion method in diesel engine decreased soot emissions. Soot emissions were much lower with Bpi1, but soot emissions increased slightly with Bpi2 compared to Bpi1.

In addition, engine performance and pollutant emissions can further improved by multi postinjection strategies. The positive results obtained with direct blend fuel in simulation post injection strategy applications showed that direct blend fuel can be applied at certain rates in real post injection experiments.

\section{References}

1. Smith CJ, Forster PM, Allen M, Fuglestvedt J, Millar RJ, Rogelj J, et al. Current fossil fuel infrastructure does not yet commit us to $1.5{ }^{\circ} \mathrm{C}$ warming. Nature Communications 2019;10. doi:10.1038/s41467-018-07999-w.

2. EPA. Sources of Greenhouse Gas Emissions 2019. https://www.epa.gov/ghgemissions/sourcesgreenhouse-gas-emissions (accessed November 28, 2019).

3. Tongroon M, Saisirirat P, Suebwong A, Aunchaisri J, Kananont M, Chollacoop N. Combustion and emission characteristics investigation of diesel-ethanol-biodiesel blended fuels in a compression-ignition engine and benefit analysis. Fuel 2019;255. doi:10.1016/j.fuel.2019.115728.

4. Chong HS, Park Y, Kwon S, Hong Y. Analysis of real driving gaseous emissions from light-duty diesel vehicles. Transportation Research Part D: Transport and Environment 2018;65:485-99. doi:10.1016/j.trd.2018.09.015.

5. Pedrozo VB, May I, Dalla Nora M, Cairns A, Zhao H. Experimental analysis of ethanol dual-fuel combustion in a heavy-duty diesel engine: An optimisation at low load. Applied Energy 2016;165:166-82. doi:10.1016/j.apenergy.2015.12.052.

6. He T, Chen Z, Zhu L, Zhang Q. The influence of alcohol additives and EGR on the combustion and emission characteristics of diesel engine under high-load condition. Applied Thermal Engineering 2018;140:36372. doi:10.1016/j.applthermaleng.2018.05.064.

7. Rakopoulos CD, Rakopoulos DC, Kosmadakis GM, Papagiannakis RG. Experimental comparative assessment of butanol or ethanol diesel-fuel extenders impact on combustion features, cyclic irregularity, and regulated emissions balance in heavy-duty diesel engine. Energy 2019;174:1145-57. doi:10.1016/j.energy.2019.03.063.

8. Tutak W, Jamrozik A, Pyrc M, Sobiepański M. A comparative study of cocombustion process of diesel-ethanol and biodiesel-ethanol blends in the direct injection diesel engine. Applied Thermal Engineering 2017;117:155-63.

doi:10.1016/j.applthermaleng.2017.02.029.

9. Satgé De Caro P, Mouloungui Z, Vaitilingom G, Berge JC. Interest of combining an additive with diesel-ethanol blends for use in diesel engines. Fuel 2001;80:565-74. doi:10.1016/S0016-2361(00)00117-4.

10. Xiao Z, Ladommatos N, Zhao H. The effect of aromatic hydrocarbons and oxygenates on diesel engine emissions. Proceedings of the Institution of Mechanical Engineers, Part D: Journal of Automobile Engineering 2000;214:307-32. doi:10.1243/0954407001527448.

11. Bilgin A, Durgun O, Şahin Z. The effects of diesel-ethanol blends on diesel engine performance. Energy Sources 2002;24:431-40. doi:10.1080/00908310252889933. 
12. Kim HY, Ge JC, Choi NJ. Effects of Ethanol-Diesel on the Combustion and Emissions from a Diesel Engine at a Low Idle Speed. Applied Sciences 2020;10:4153. doi:10.3390/APP10124153.

13. Çelebi Y, Aydın H. Investigation of the effects of butanol addition on safflower biodiesel usage as fuel in a generator diesel engine. Fuel 2018;222:385-93. doi:10.1016/j.fuel.2018.02.174.

14. Shahir SA, Masjuki HH, Kalam MA, Imran A, Fattah IMR, Sanjid A. Feasibility of diesel-biodiesel-ethanol/bioethanol blend as existing CI engine fuel: An assessment of properties, material compatibility, safety and combustion. Renewable and Sustainable Energy Reviews 2014;32:379-95. doi:10.1016/j.rser.2014.01.029.

15. Lapuerta M, Armas O, García-Contreras R. Stability of diesel-bioethanol blends for use in diesel engines. Fuel 2007;86:1351-7. doi:10.1016/j.fuel.2006.11.042.

16. Datta A, Mandal BK. Impact of alcohol addition to diesel on the performance combustion and emissions of a compression ignition engine. Applied Thermal Engineering 2016;98:670-82.

doi:10.1016/j.applthermaleng.2015.12.047.

17. Tongroon M, Saisirirat P, Suebwong A, Aunchaisri J, Kananont M, Chollacoop N. Combustion and emission characteristics investigation of diesel-ethanol- biodiesel blended fuels in a compression-ignition engine and bene fi t analysis. Fuel 2019;255:115728. doi:10.1016/j.fuel.2019.115728.

18. Kwanchareon P, Luengnaruemitchai A, Jai-In S. Solubility of a diesel-biodiesel-ethanol blend, its fuel properties, and its emission characteristics from diesel engine. Fuel 2007;86:1053-61.

doi:10.1016/J.FUEL.2006.09.034.

19. Redel-Macías MD, Pinzi S, Babaie M, Zare A, Cubero-Atienza A, Dorado MP. Bibliometric Studies on Emissions from Diesel Engines Running on Alcohol/Diesel Fuel Blends. A Case Study about Noise Emissions. Processes 2021;9:623. doi:10.3390/PR9040623.

20. Ribeiro NM, Pinto AC, Quintella CM, da Rocha GO, Teixeira LSG, Guarieiro LLN, et al. The Role of Additives for Diesel and Diesel Blended (Ethanol or Biodiesel) Fuels: A
Review. Energy \& Fuels 2007;21:2433-45. doi:10.1021/ef070060r.

21. Gürbüz H. Modeling of the effects of post injection on emissions in hybrid use of a diesel-ethanol fueled engine. Ph.D Thesis, Y1ldı Technical University, 2019.

22. Kuszewski H, Jaworski A, Ustrzycki A, Lejda K, Balawender K, Woś P. Use of the constant volume combustion chamber to examine the properties of autoignition and derived cetane number of mixtures of diesel fuel and ethanol. Fuel 2017;200:564-75. doi:10.1016/j.fuel.2017.04.021.

23. Murphy MJ, Taylor JD, Mccormick RL. Compendium of Experimental Cetane Number Data. National Renewable Energy Laboratory 2017:1-48. doi:10.2172/1086353.

24. Schöpe M. Renewable energy directive. European Wind Energy Conference and Exhibition 2008 2008;1:32-8.

25. ICCT. Final recast RED II: Renewable Energy Directive for 2021-2030 in the European Union. 2018.

26. Rakopoulos DC, Rakopoulos CD, Kakaras EC, Giakoumis EG. Effects of ethanoldiesel fuel blends on the performance and exhaust emissions of heavy duty DI diesel engine. Energy Conversion and Management 2008;49:3155-62.

doi:10.1016/j.enconman.2008.05.023.

27. Rossomando B, Arsie I, Pianese C. Analysis of the impact of Diesel-Ethanol fuel blends on CI engine performance and emissions via multi-zone combustion modelling. Energy Procedia, vol. 126, Elsevier Ltd; 2017, p. 105966. doi:10.1016/j.egypro.2017.08.203.

28. Huang J, Wang Y, Li S, Roskilly AP, Yu $\mathrm{H}$, Li H. Experimental investigation on the performance and emissions of a diesel engine fuelled with ethanol-diesel blends. Applied Thermal Engineering 2009;29:2484-90. doi:10.1016/j.applthermaleng.2008.12.016.

29. Petranović Z, Edelbauer W, Vujanović M, Duić N. Modelling of spray and combustion processes by using the Eulerian multiphase approach and detailed chemical kinetics. Fuel 2017;191:25-35. doi:10.1016/j.fuel.2016.11.051.

30. Ozener O, Ozkan M, Yuksek L. Modelling analysis of multiple diesel injection strategies with one-dimensional simulation coupled with artificial neural networks. Thermal 
Science

$2017 ; 21: 413-25$. doi:10.2298/TSCI1605042230.

31. Padala S, Woo C, Kook S, Hawkes ER. Ethanol utilisation in a diesel engine using dualfuelling technology. Fuel 2013;109:597-607. doi:10.1016/j.fuel.2013.03.049.

32. Arrègle J, Pastor J V., López JJ, García A. Insights on postinjection-associated soot emissions in direct injection diesel engines. Combustion and Flame 2008;154:448-61. doi:10.1016/j.combustflame.2008.04.021.

33. Lopez JJ, Martin J, Garcia A, Villalta D, Warey A, Domenech V. Characterization of incylinder soot oxidation using two-color pyrometry in a production light-duty diesel engine. SAE Technical Papers 2016;2016. doi:10.4271/2016-01-0735.

34. Tsurushima T, Zhang L, Ishii Y. A study of unburnt hydrocarbon emission in small di diesel engines. SAE Technical Papers, SAE International; 1999. doi:10.4271/1999-01-0512. 35. Nabi MN, Rasul M, Gudimetla P. Modelling and simulation of performance and combustion characteristics of diesel engine. Energy Procedia, vol. 160, Elsevier Ltd; 2019, p. 662-9. doi:10.1016/j.egypro.2019.02.219.

36. Tutak W, Jamrozik A, Bereczky Á, Lukacs K. Effects of injection timing of diesel fuel on performance and emission of dual fuel diesel engine powered by diesel/E85 fuels. Transport 2018;33:633-46. doi:10.3846/transport.2018.1572.

37. Heywood JB. Internal combustion engine fundamentals. McGraw-Hill; 1988.

38. GmbH AL, editor. AVL BOOST User Guide version 2018,. Graz, Austria: AVL LIST $\mathrm{GmbH} ; 2018$.

39. Woschni G. A universally applicable equation for the instantaneous heat transfer coefficient in the internal combustion engine. SAE Technical Papers, SAE International; 1967. doi:10.4271/670931.

40. Brunt MFJ, Platts KC. Calculation of heat release in direct injection diesel engines. SAE Technical Papers, SAE International; 1999. doi:10.4271/1999-01-0187.

41. Broekaert S, De Cuyper T, De Paepe M, Verhelst S. Evaluation of empirical heat transfer models for HCCI combustion in a CFR engine. Applied Energy 2017;205:1141-50. doi:10.1016/j.apenergy.2017.08.100.

42. Park SH, Yoon SH, Suh HK, Lee CS.
Effect of the Temperature Variation on Properties of Biodiesel and Biodiesel-Ethanol Blends Fuels. Oil \& Gas Science and Technology - Revue de l'IFP 2008;63:737-45. doi:10.2516/ogst:2008038.

43. Garai A, Mondal S, Pal S, Chatterjee S, Sen S, Mukhopadhyay A. Experimental investigation of spray formation in a hybrid atomizer using diesel, ethanol and ethanol blended diesel. Experimental Thermal and Fluid Science 2019;100:158-70. doi:10.1016/j.expthermflusci.2018.09.003.

44. Li X, Cheng Y, Ji S, Yang X, Wang L. Sensitivity analysis of fuel injection characteristics of GDI injector to injector nozzle diameter. Energies 2019;12. doi:10.3390/en12030434.

45. Payri R, Gimeno J, Marti-Aldaravi P, Vaquerizo D. Internal flowcharacterization on an ECN GDi injector. Atomization and Sprays 2016;26:889-919.

doi:10.1615/AtomizSpr.2015013930.

46. Prabakaran B. Utilization of DieselEthanol Blends in a CI Engine as a Fuel with Nano Alumina as Combustion Enhancer. SAE Technical Papers, vol. 2018- July, SAE International; 2018. doi:10.4271/2018-28-0010. 47. Armas O, García-Contreras R, Ramos Á. Pollutant emissions from New European Driving Cycle with ethanol and butanol diesel blends. Fuel Processing Technology 2014;122:64-71.

doi:10.1016/j.fuproc.2014.01.023.

48. Wu Y, Wang P, Muhammad Farhan S, $\mathrm{Yi}$ J, Lei L. Effect of post-injection on combustion and exhaust emissions in DI diesel engine. Fuel 2019;258:116131. doi:10.1016/J.FUEL.2019.116131.

49. Tse H, Leung CW, Cheung CS. Investigation on the combustion characteristics and particulate emissions from a diesel engine fueled with diesel-biodiesel-ethanol blends. Energy 2015;83:343-50. doi:10.1016/j.energy.2015.02.030.

50. Desantes JM, Arrègle J, López JJ, García A. A comprehensive study of diesel combustion and emissions with post-injection. SAE Technical Papers 2007;2007-01-09:11. doi:10.4271/2007-01-0915. 